\title{
Identity, Glass Borders and Globally Mobile Female Talent
}

\begin{abstract}
Purpose - The purpose of this paper is to explore the interplay between identity and global mobility in the careers of senior, female talent, uniquely taking into account the perceptions of both female and male participants. In addition, the role organizations can play in enabling women to overcome these identity constraints is identified.
\end{abstract}

Design - This interpretivist study draws on data from 38 in-depth interviews with senior managers in a large, multinational organization to elicit a rich picture of how such careers are enacted.

Findings - Findings reveal how identity conflicts function as a glass border for globally mobile, senior female talent. Ways in which talent can access positive identity narratives to inform global mobility choices are identified.

Research Limitations/Implications - The limitations of this study include the relatively small sample size and the single case design of this research. The findings, however, offer insights into the identity work of globally mobile, female talent across different contexts.

Practical Implications - Organizations can facilitate access to identity narratives through mentoring, face-to-face forums and via the Internet to enable globally mobile, female talent to make more informed global mobility choices.

Originality/Value - Drawing on identity theory, this paper examines how identity work for globally mobile, female talent has more fluid interpersonal boundaries than for men, creating on-going identity struggles. In highlighting how identity narratives can act as a means of breaching the glass border and facilitating global mobility for female talent, a contribution is made to existing debates in the fields of identity, gender studies and global talent management.

\section{Paper type Research Paper}

Keywords women, glass ceilings, global mobility, identity, organizational support

\section{Introduction}

Forms of global mobility have been expanding over the past twenty years (Kirk, 2016), but shortages in globally mobile talent have increasingly been reported (Böhmer and Schinnenburg, 2016). Talent is defined here as 'a bench of high potentials located in the talent pipeline and, a senior leadership suite, which potentials aspire to' (Groutsis et al., 2018, p. 2232). Global mobility, as Bozionelos et al. (2017, p. i ) note, 'takes many forms, ranging from short duration assignments that do not repeat themselves to long-term 
expatriate assignments either initiated by the employing organization or self-initiated'. The focus in this paper is on the international careers of senior, female 'talent' who engage in numerous forms of global mobility including traditional expatriation (1-5 years), short-term assignments (less than 1 year), localised transfers from one business unit to another, global commuting and business travel (Bozkurr and Mohr, 2011).

This paper is a response to calls for research into how such international careers are enacted from a female perspective (McNulty and Hutchings, 2016) as travelling for work remains "a gendered experience" (Jeong et al, 2013, p. 148). Only 25\% of those engaged in expatriate assignments are female (Brookfield, 2016), however there is no available data showing numbers of individuals involved in business travel or global commuting. Gender inequality in talent management schemes act as barriers to women's progression (Festing et al., 2015), thus globally mobile, female talent, despite having apparently broken through the glass ceiling, remains vulnerable to isolation and marginalization (Beirne and Wilson, 2016). Glass ceiling is defined here as a "subtle, impenetrable barrier that blocks women and minorities' advancement in a management hierarchy; they can be promoted below the barrier - but not across it" (Zeng, 2011, p. 312).

It is argued in this paper that women face an additional glass ceiling in the form of identity conflicts resulting from trying to balance multiple roles and identities, and this exacerbates the difficulties they face in being globally mobile. The aim of the study is to explore how identity impacts on barriers facing globally mobile, female talent, thereby offering a contribution to the literature on identity, gender studies and global talent management. The two research questions that have guided this study are therefore: 
RQ1. What impact does identity have on senior, female managers' pursuit of different forms of mobility inherent in a globally mobile career?

Secondly, in response to calls for studies that explore how the glass ceiling might be shattered (Powell and Butterfield, 2015):

RQ2. What role can organisations play in enabling women to overcome identity constraints and enact globally mobile careers?

\section{Literature Review}

\section{Barriers to Women}

Drawing on the work of Adler (1979), Cross and Lineham (2006) assert that women face a self-imposed glass ceiling in their working lives. This barrier is related to the priority they attach to their caring role, the need to balance their personal lives and careers and, in turn, their identity construction. In spite of female participation in the labour market increasing (Dang et al., 2014), there is evidence of under-representation of women in senior talent pools (Powell and Butterfield, 2015). This has been attributed to discrimination against women epitomised in the metaphor 'the glass ceiling' which has dominated gender studies since the 1980s.

The nature of these barriers has been documented elsewhere. For example, it has been argued that women face an invisible 'firewall' (Bendl and Schmidt, 2010) where 'outsiders' cannot gain access to 'the system' as the rules are established and maintained by the (male) insiders. Others have suggested that glass escalators exist where men who work in typically female occupations have better internal promotion prospects than women in the same occupations (Hultin, 2003). Some assert that there are 'sticky floors' that are reflective of the lower average wages of women relative to men (Christofides et 
al., 2013). Gender differences in external hiring creates glass doors (Hassink and Russo, 2010) and even when women are promoted, they are often offered opportunities in organisations which are facing difficult circumstances and thus face a so-called 'glass cliff' as they have to rise to even greater challenges than their male counterparts (Ryan and Haslam, 2011). Women in such 'high risk' positions, who may lack support and/or authority are at greater risk of being fired than men (Glass and Cook, 2016). There are additional barriers facing women in global careers, as the next section highlights.

\section{Barriers to Women in Global Careers}

Barriers extend to women in globally mobile careers with images of glass borders (Lineham and Walsh, 1999) being added in recognition of the increasingly international nature of contemporary careers. Despite the myth that women do not want international assignments being discredited (Adler, 1979), a lack of globally mobile, female talent remains (Varma and Russell, 2016). Although expatriate numbers continue to rise (Brewster et al., 2014), women are often confined to domestic enterprises whilst men increasingly occupy senior positions in multinational or global businesses (Tienari et al., 2010).

The reluctance to send women on international assignments continues to be of concern not only from an ethical perspective, but also from a logistical one (Insch et al., 2008) as it limits the already scarce talent pool (Powell and Butterfield, 2015). It has also been noted that expatriate women face more challenges than men (Mäkela et al., 2017). These barriers also relate to other forms of global mobility and is attributable to a variety of reasons including; identity constraints exacerbated by bias in selection for assignments 
and promotion; inequitable gender power relations; and a lack of organisational support. These are considered in the following sections.

\section{Identity Work \& Women}

Identity is defined here as, 'The individual's own notion of who and what they are' (Watson, 2008, p. 131). It has an internal dimension (self-image) related to how we see ourselves and how we would like others to see us and an external orientation (public image), which is how others categorise us. 'Humaness', ethnicity and gender all form part of an individual's 'primary identities', are 'implicated in many contexts', reinforced through socialisation and are resistant to change (Jenkins, 2000, p.21). Identity work is thus a process of internal self-reflection and social interaction with others through which individuals define and redefine themselves (Jenkins, 2014). In other words, it is the process through which different identities (such as work identity, maternal identity, etc.) is crafted and re-crafted over time.

It has been claimed that this process of identity work for women is more complex and relational (Ely and Meyerson, 2010) leading to calls to explore to what extent female identities have more fluid interpersonal boundaries (Brown, 2015). This complexity and fluidity, it is argued here, may be magnified for women identified as talent, as although such categorisation (Jenkins, 2000) can act as a motivator, paradoxically, it can have the opposite effect as it is associated with higher expectations and demands (Daubner-Siva et al., 2018). Such labelling is especially the case, it is contended, for those identified as global female talent, as compared to women in domestic roles. 


\section{Identity and Mobility}

Identity is associated with mobility as it also emerges through an individual's interaction within a context or place (Scurry et al., 2013). It is not just being immersed in a new cultural environment that impacts on identity, it is also the process of choosing whether or not to accept such an opportunity. Such choices can also result in higher levels of stress, anxiety and identity struggles (De Boeck et al., 2018) creating an additional disadvantage to women, many of whom already juggle multiple roles and identities (Painter-Morland, Kirk, Deslandes and Tansley, 2018). Those who are globally mobile, face an extra level of complexity as individuals need to engage in identity work that enables them to cope with 'perpetually shifting assignments, relationships and locations' (Tansley and Tietze, 2013, p.1813).

For women who are required (or choose to) relocate, cultural and religious attitudes can constrain positive identity work, making global careers even more challenging (Scurry et al., 2013). Furthermore, gender discrimination at institutional level in some countries can lead to harassment for female expatriates (Bader et al., 2018). Thus international assignments invoke a change in identity (Kohonen, 2005; Mao and Shen, 2015), but the same is true, it is argued, for all forms of global mobility (Kirk, 2016).

The extent to which lower female numbers can be attributed to a lack of willingness to engage in global mobility is unclear. Research indicates that women are less globally mobile than men, especially when there are children in the family (Lirio, 2014). This is particularly true of in terms of travelling to locations perceived to be dangerous (Stoermer et al., 2017). It is suggested that women impose a glass ceiling on themselves as they 
evaluate the costs and benefits of accepting expatriate assignments, with the deciding factor being the impact taking that role will have on their work-life balance (Cross and Lineham, 2006).

Women are positioned as being 'powerlessly caught in a penalising structural context' (Janssens et al., 2006, p. 133) as they seek to respond to societal discourses that emphasise their maternal roles and de-emphasise their identities as successful, working women. This is particularly the case in some developing countries, where attitudes to women's domestic roles inhibits global mobility (Hutchings and Michailova, 2017). It is true to say, however, that in some contexts, such as East Asia, the Caribbean and North Africa, access to low-cost, high quality childcare can offer women a means of reconciling their role and identity conflicts (Shortland, 2018). Although each society has its own prevailing expectations, beliefs and cultural values that influence attitudes to motherhood and the outcome of such competing discourses is by no means certain (Duberley and Carrigan, 2012). However, other constraints, such as bias in selection impact on the way in which women construct and reconstruct their identities and their ability to be globally mobile, as discussed next.

\section{Bias in Selection}

The percentage of female expatriates has risen, but they remain underrepresented due to on-going gender bias in selection for global assignments (McNulty and Hutchings, 2016). Furthermore, men are more likely to select other men for international assignments for the same reasons (Varma and Russell, 2016). Women are also perceived to need managerial experience prior to the international appointment; a condition that male managers are not subject to, thus making them less likely to be chosen ( $\mathrm{Ng}$ and Sears, 
2017). Women are also required to hold higher qualifications than their male colleagues (Caliguiri and Bonache, 2016). All these factors also influence the identity work of female talent as they react to the way in which they are treated by others. In addition, power differentials in mentoring relationships present a further barrier, as discussed below.

\section{Inequitable Power Relations}

A shortage of female mentors including access to networks for women (Sugiyama et al., 2018) creates challenges for globally mobile women. Furthermore, women from nonWestern cultures and those with higher power distance and low gender egalitarianism gain less from mentor relationships than those with lower power distance and high gender egalitarianism, as they tend to adopt more submissive attitudes and can be subject to abuses of power by their mentor. This can impact on their career progression (Ramaswami et al., 2013) and self-image (Jenkins, 2000) by deterring or even preventing them from seeking opportunities to be globally mobile. A lack of organisational support can also impact on how individuals craft and re-craft their identities and reinforce the glass ceiling, as explored in the next section.

\section{Lack of Organisational Support}

Research in the field has tended to focus on expatriation and the organisational support that female expatriates require (see for example, McNulty and Hutchings, 2016; HoweWalsh and Torka, 2017), including for dual-career couples (Sugiyama et al., 2018).

There are only a few studies exploring other forms of global mobility, such as business travel (Trzebiatowska, 2010) and business travel, short-term assignees and international commuters (Mäkelä et al., 2017). Even fewer researchers have explored other forms of global mobility from a female perspective, a notable exception being Puchmüller and 
Fischlmayr's (2017) study into the emotional, instrumental and informational support needed by female business travellers.

An image emerges of a multi-layered, glass ceiling maintained by attitudes of both men and women in certain cultural contexts, imposed and enforced in others through gender bias by men and by women through identity conflicts. An area that remains largely unexplored, is the support that organisations can offer in terms of facilitating identity construction for those enacting globally mobile careers. This is particularly pertinent for women, who experience conflict in reconciling their multiple identities, which is further exacerbated by the challenges inherent in the careers of senior female talent, who are often subject to greater scrutiny than their male counterparts (Glass and Cook, 2016), and thus need additional support. Hence the research questions identified to guide this study.

\section{Methodology}

This qualitative, interpretivist study, was designed to gather empirical data for a $\mathrm{PhD}$ funded jointly by the ESRC and a sponsoring organisation. It was designed to examine how identity impacts on senior, female managers' ability to successfully pursue a globally mobile career. The case organisation, a large multinational with a presence in over 70 countries worldwide, covers nine diverse sectors from animal nutrition to transportation and logistics, giving a broad scope in terms of types of business. The scale of this research, unlike many other studies in the field, is not confined to expatriation but includes a wide range number of forms of mobility. Theoretical sampling (Huberman and Miles, 2002) was used to work with a case organisation contact to purposively select particular individuals who served to illustrate differing examples of the concepts in the study, i.e. those faced with global mobility choices operating in different cultures and contexts 
across the case organisation. These were employed across the global businesses in supply chain, global diversity, HR, organisational effectiveness and corporate business units.

A pilot was conducted prior to commencement and this informed the interview protocol (see Appendix 1). A total of 38 interviews were conducted, 16 with senior female talent and 22 with men. The sample selected was representative of the target population in terms of age, gender, ethnicity, length of service, etc. A combination of in-depth, semi-structured, face-to-face and telephone interviews by the author were carried out, 11 of which were face-to-face in the head offices of the case organisation in America. This necessitated visiting the participants in their offices across the corporate site, thus enabling the researcher to observe their body language; however, a drawback was the occasional phone call interruption. The remaining interviews were undertaken by telephone due to the challenges presented by both the global mobility of the participants and the geographic locations in which they were based.

The 'relative anonymity' that telephone interviews might be seen to provide (Sturges and Hanrahan, 2004 p.108) was useful as some of the issues raised by participants were quite personal in nature. Having no visual cues, such as body language, was a slight disadvantage; however, it did enable the researcher to focus on subtler nuances (such as pauses, sighs, etc.) and pay closer attention to the stories being told (Holt, 2010). Furthermore, these participants are very accustomed to the use of technology, such as Skype, videoconferencing, etc. to communicate (Trier-Bieniek, 2012 p.630) and the richness of the data and the length of the interviews bears testimony to their level of comfort with this research method.

The duration of the interviews varied, as might be expected in open, exploratory studies of this nature, ranging from an hour's duration up to $2 \frac{1}{2}$ hours in length. The interviews 
were digitally-recorded and transcribed. The table below shows the sample profile. Pseudonyms have been used to protect participants' privacy.

-Insert Table 1.0 Sampling Profile about here-

\section{Data Analysis}

With respect to data analysis, an iterative approach was taken to identify preliminary themes from the data. This prevented a blinkered view being adopted by developing a priori codes (Gioia et al., 2013). Frequency of recurring themes and observations from transcripts were noted in order to give an indication of the strength of shared feeling; however, the focus was also on the narratives told by participants which reflected details of the culture(s) in which these individuals work. The stories the women told about the identity constraints on their globally mobile careers was of primary interest.

In the interviews, both female and male participants were asked what they perceived to be the identity barriers and facilitators for women to being globally mobile. The themes from the interviews were connected in a recursive and analytical approach to identify not only what were perceived to be the challenges associated with an international career but also what support employers might offer to enable them to overcome these.

Following the approach adopted by Gioia et al. (2013, p.18), $1^{\text {st }}$ order codes were identified, i.e. those 'informant-centric terms' that epitomised the lived experiences described by these individuals. These included: 'lack of work-life balance'; 'dependants as a barrier'; 'fear of saying no', etc. which were linked to the $2^{\text {nd }}$ order, 'theory-centric' 
theme: 'a change in the permeability of the glass ceiling', making it harder to penetrate. This resulted in the identification of the aggregate dimension of 'triggering identity struggles'. The $1^{\text {st }}$ order codes being offered a 'flexible approach to global mobility' and 'freedom to share information' were linked to $2^{\text {nd }}$ order themes such as 'feelings of agency' and the ability to 'access identity narratives' to inform mobility choices. This led to the identification of the aggregate dimension of 'a reduction in the glass border facing female talent'. Such organisational support enabled 'flexible careers' which is encapsulated in the aggregate dimension an 'ethical approach to global talent management'. To avoid definitional drift, as only one researcher was conducting the analysis, memos were written to record the rationale for codes identified and constant comparisons were made between the original codes and those generated as the analysis progressed, as advocated by Gibbs (2018).

- Insert Table 2.0 Coding and Themes about here -

The following section details the findings from the study and highlights the factors that result in identity struggles for many globally mobile talented females, as well as those that lead to a reduction in the glass border.

\section{Findings}

\section{Saying No to Global Mobility}

For a number of globally mobile women in this study, 'mother' was an imbedded source of identity (Kohonen, 2005). Norma Stevens, a director, said she had declined to accept expatriate assignments opting to engage in flexpatriate assignments, globetrotting and, where necessary take short-term assignments (See Table 1.0) instead explaining; 'I 
believe what's most important to many of us as women is our children'. However, for some participants the non-work identity of mother is a career barrier, creating an impenetrable wall which they feel can only be breached by seeking an alternative source of employment, as Sylvia Hughes, a senior Human Resources Manager, recounted:

I know of a case very well; this younger woman has young children and the expectations in her current role, she cannot balance that need to be with the children. So she has felt uncomfortable raising it, but feels, if need be she'll go and work somewhere else.

This collision between work and non-work roles results in identity struggles, but even for those women without children, there may be caring roles that impact on their ability to engage in all forms of global mobility. Kirstin Shore, a Global Diversity and Inclusion Manager, explained how currently she will only agree to global trotting, rather than relocation:

I mean right now technically you'd think I would be able to, single with no children. Plus I'm global, I'm interested, but I've got other considerations right now in my life stage with my parents and whatnot, so it doesn't make sense for me right now.

A number of male colleagues recognised these barriers for women in the talent pool and expressed empathy. Elias Koffman, a Corporate Vice President, expressed shock when he realised how some women feel:

My eyes got opened. I had to give a talk on the Middle East in a [case organisation] Women's Forum. I did my spiel on the Middle East and then listened...there was 104 women from all over the world and the anguish, these women felt like God, 
I've just had a baby, but I didn't want to tell I didn't want to come because they won't invite me again.

Sylvia Hughes', Lead Human Resources, children have now grown up and left home and her parents have passed away. She explained how until now, she had only been prepared to engage in globe-trotting and short-term assignments. This was the first time in her career, as an 'empty-nester', she has felt able to accept an expatriate assignment and how she perceives identity tensions negatively affected her global mobility career choices and those of other senior women within the case organisation:

For women earlier in their career it is a major obstacle to overcome. Number one the career break or at least downturn that many women have. Number two, the negative response from leaders and men in the company about women taking career break or potentially taking career breaks or not accepting an assignment at a point in time because of family issues.

However, agreeing to be globally mobile, in whatever form, also comes with a cost, as the next section shows.

\section{Guilt}

Many of the women interviewed expressed feelings of guilt at the compromises they have to make affecting their family's lives. Lynette Winter, a Global Leadership Talent Manager who regularly accepts expatriate assignments and also engages in frequent globe-trotting, explains how her husband is much less mobile in his career than her and therefore provides much of the childcare for their son. This clearly causes Lynette identity issues as she recounts an occasion when her husband's work took him abroad and 
how her young son said he didn't like his father travelling. Lynette wryly says when she asked him if he missed her when she was away, he said no. In attempting to make sense of her roles as mother and talented leader, she says the answer made her 'glad and not glad.' This illustrates the talent paradox, where being identified as talent is a source of motivation, but also brings the pressure of higher expectations. In the case of globally mobile women, it is argued here, these pressures are further magnified.

\section{Selfishness}

Lynette's case of a less mobile husband was a rare example in the study. Most female participants expressed the view that the forms of global mobility they would be prepared to engage in are constrained by their identity as carer. Their male colleagues suggested that the reasons for this were twofold; firstly, that men are not inclined to adjust their careers to accommodate that of their partners, as Jeffrey Vine, a senior manager, said:

The women will follow men wherever they go, etc. I know that's very old fashioned but if its part of our culture today and it's not that common to see that men are prepared to quit their jobs for the international experience for their wives.

Secondly, it was perceived that men are more selfish than women with regard to their careers, as Jim Regan, a President, stated:

I have countless examples of women who had very nice careers, but they were willing to sacrifice their career for their husband. And so for whatever reason women do seem to be a lot less selfish than men about their careers.

All female participants said that it wasn't willingness that made women sacrifice their careers for men, more that many men were not inclined to make compromises in their careers. In other words, women felt they had no choice. There was a lot of sympathy 
expressed by the male participants for their female colleagues with regard to the demands of being in a global talent pool, as Mark Edwards, an HR Manager, admitted:

I do think potentially there are more challenges [for women] to a certain extent because I think being a male you tend to think, the wife will give up her job and come with me. But if I put myself in the situation where if my wife had been working and said, I've got an opportunity to go to Belgium will you give up your job and come with me, it would have been a heck of a decision.

Terence Greenhall, an Organisational Effectiveness Consultant, endorsed this view saying:

... I think there's also a barrier or perceived barrier, you know, guys are jerks and we do it anyway, we drag family with us; women tend to be more thoughtful and think of the impact of it.

For the majority of those interviewed, such opportunities for identity re-construction are not unproblematic as having multiple, competing identities acts as a barrier to global mobility (and by association, to career progression). For female managers who are experiencing such identity conflicts, more support is needed to enable them to make sense of the global mobility choices they might make. This support can take a number of forms, as the discussion in the next section shows.

\section{Support for Globally Mobile Women}

The female managers interviewed unanimously asserted that women are no less willing than their male counterparts to be mobile, but that their mobility needs to be facilitated through appropriate organisational support. All participants in this study, regardless of 
age, ethnicity, length of service or the form of mobility engaged in, stressed the need for both emotional and instrumental support. Perhaps this is because all identified some caring role, whether for parents or children. There were some differences in the perceived support needed depending on the form of global mobility engaged in. For instance, women engaging in business travel suggested that Skype rather than face-to-face meetings would reduce the amount of unnecessary travel helping them with child care issues.

However, regardless of the form of mobility, one of the key issues was perceived to be a need for a flexible approach to managing global mobility to enable women to balance the demands of their multiple identities. As Joanne Westwood, a Human Resource Manager with young children and who will only engage in globe-trotting, put it:

I think our biggest issues is, if we are going to be a high potential talent vehicle and we're going to have women in diverse going through the organisation, we have to be flexible and adaptable to meet the needs that they have.

The global mobility policy, participants felt, should encompass alternatives to international travel, such as, for example, video conferencing, etc. They also referred to the need to enable women (and men) to manage dual careers by ensuring that appropriate timings were jointly negotiated for global mobility assignments. Through this, the identity struggles experienced by the women can be lessened by allowing the needs of both partners to be accommodated. The acceptance of a variety of forms of global mobility (such as shorter assignments and frequent business travel) were seen by many of both the male and female respondents to offer a solution to relocating a partner and family. This was seen to be particularly important as even on expatriate assignment, respondents 
reported that they were still required to engage in other forms of global mobility, such as globetrotting, to manage operations. Being able to negotiate alternative forms of global mobility clearly reduces identity conflict for some women as Sian Byers, Head of Leadership and Talent Management, explained:

I travel quite a bit, with a daughter who has just graduated from high school, the stress associated with travel was much lower than the stress that would have been associated with moving her somewhere else.

A number of participants emphasised how being able to share experiences and exchange stories helps them make global mobility choices and reduce identity conflict, as Norma Stevens, a Director, explains:

And people can.. learn about different stories. You know... like what colour is my parachute stuff out on the web, what are my values and interests and skills and what does that equal.

Sian Byers described how she and others have been deterred from some global mobility opportunities because they perceive that asking questions about the implications of the role could be seen as evidence of a lack of commitment. Individuals in situations such as this give and receive support and guidance from each other through the process of storytelling:

I'm thinking about the people who've shared stories with me about even interviewing for a role because they felt that all these questions were taboo that they really needed to understand the commitment and the impact on their personal life.

In attempts to break through the barriers that women face in enacting a globally mobile career, stories provide a means of accessing identity narratives that assist in reconciling 
identity conflicts. Given the additional complications in terms of time differences and geographic distance, technology can also be used to facilitate such communications.

\section{Discussion}

The aim of this study was twofold; to explore the interplay between identity and global mobility in the careers of senior female talent and to identify the role organisations can play in enabling women to overcome identity constraints. Work in the field has tended to focus on the more tangible aspects of the so-called 'glass-border' (Lineham and Walsh, 1999) with a few studies exploring the role identity plays in the cultural adjustment of expatriates (Glanz, 2003; Kohonen, 2005; Scurry et al., 2013); however, this study is unique in that it explores the relationship between identity and different forms of global mobility from the perspectives of both male and female talent.

The findings from this study show globally mobile, talented women face not only external pressures, they also experience internal, identity conflicts. Non-work roles and associated primary identities (Jenkins, 2000), such as mother, daughter collide creating tension for women. The pressure of also being categorized as globally mobile and talented brings into conflict the self- and public image of the women's identities (Jenkins, 2014) exacerbating these identity struggles and creating stress. The results from this research show that, although male colleagues empathised with some of the barriers facing their counterparts, there were aspects that they didn't appreciate, such as the embeddedness of some aspects of female identities. Furthermore, the unwillingness of men to make compromises in terms of their own careers clearly increases the pressure on women to continue to make sacrifices in their own working lives. 
Identity evidently serves as a key influence for women with respect to the forms of global mobility they are prepared to engage in. For those with dependants, relocation appears to be the least desirable option due to the disruption it causes for their family. Reasons offered for this were that being able to engage in globe-trotting, flexpatriation and occasional short-term assignments created less stress for the family than having to move them to another country. This is especially the case in the light of constantly changing business needs. These women clearly experience identity struggles in striving to match the perceived expectations (including those embedded in their own self-image) of their roles as mothers, daughters, wives, etc. Being identified as global talent further exacerbates this self-conflict.

Men, on the other hand, do not appear to fully appreciate the tensions suffered by their female colleagues or to experience such problems in separating home and work life. This shows how for globally mobile, female talent, the process of internal self-reflection and external engagement with others is a continual, somewhat fraught dialectic. This suggests that identity work for globally mobile, female talent has more fluid interpersonal boundaries than for their male counterparts and responds to calls by Brown (2015) for further research into how gender influences identity work.

The importance of instrumental and emotional support for all forms of globally mobile talent, not just business travellers (Puchmüller and Fischlmayer, 2017) is underscored by the findings from this study. There is a need to negotiate with global, female talent to identify 'strategic windows of opportunity' (Harvey et al., 2009, p.15) where they may be able to expatriate; however, it is also important to offer flexibility over the form of mobility that can be engaged in. Access to alternative identity narratives is essential, not 
only for expatriates (Scurry et al., 2013) but, it is argued here, for any form of global mobility. Thus access to stories through mentoring, networking and via the Internet (Glanz, 2003) needs to be provided.

In focusing on a range of forms of mobility, rather than just expatriation, this article offers greater insights into the nature of globally mobile careers. In highlighting how identity narratives can act as a means of breaching the glass border and facilitating global mobility for female talent, it offers a contribution to identity theory, gender studies and global talent management.

\section{Implications for Practice}

Direct support can be offered by providing flexibility and family-friendly policies to accommodate these female workers. More specifically, allowing women to choose the form of global mobility that best suits them at any given point in their life cycle is vital. Being able to opt to engage in business travel or global commuting, rather than to relocate, consistently emerged as a means of reducing identity conflict. Secondly, as women seek to reconcile the often competing needs of their different embedded identities, they are influenced by the experiences of others to whom they can relate. Thus, organisations can facilitate indirect support by enabling stories to be exchanged, allowing individuals to make sense of their global mobility choices. Opportunities could be created to exchange these stories either face-to-face or by using technology in order to facilitate the process of positive identity construction. Such activities would allow women to access a wider range of identity discourses helping them navigate through their complex working lives and compete on a more even playing field with their male colleagues. 


\section{Conclusions}

Findings from this study show that, despite the emergence of new forms of careers and the associated discourses of individual agency and choice, in practice globally mobile female talent face barriers to being mobile due to identity conflicts that act as an internal glass ceiling and border to career progression. These struggles are exacerbated by the fact that identity work for such women has more fluid interpersonal boundaries than are faced by their male counterparts. Participants in this study indicate that it is not a lack of willingness that prevents them from being globally mobile, but a lack of organisational support in terms of gaining access to alternative identity discourses that could enable them to make more informed choices about global mobility. Furthermore, it is concluded that organisations can reduce discrimination and promote equality by offering both direct and indirect support through implementing gender-focused policies and creating opportunities (through mentoring and networking) for women to access alternative identity narratives that enable them to navigate better their work-life boundaries.

\section{Limitations and future research}

The limitations of this study include the relatively small sample size and the single case design of this research. However, given the scale of the operations in this large multinational, the findings offer insights into the impact of identity on globally mobile female talent across a number of different contexts. The results also highlight the implications for organisations in facilitating the global careers of female managers. Future research could be designed to explore the interplay between identity and global mobility across all genders and levels of the talent pool. A longitudinal study would enable researchers to gain deeper insights into how global talent identity narratives influence identity work over time, thus informing HR policy for the future. 
Funding

This work was supported by the Economic and Social Research Council (ESRC) [grant number ES/F033/09/1].

Disclosure statement

No potential conflict of interest was reported by the author. 


\section{REFERENCES}

Adler, N.S. (1979). "Women as Androgynous Managers. A Conceptualisation of the Potential for American Women in International Management". International Journal of Intercultural Relations, Vol 3. pp. 407-436.

Bader, B., Stoermer, S., Bader, K. and Schuster, T. (2018) Institutional discrimination of women and workplace harassment of female expatriates. Journal of Global Mobility: The Home of Expatriate Management Research, Vol 6, No. 1. pp. 40-58.

Beirne, M. and Wilson, F. (2016). "Running with 'wolves' or waiting for a happy release? Evaluating routes to gender equality”, Work, Employment and Society, Vol 30, No 2. pp. 220-236.

Bendl, R. and Schmidt, A. (2010). "From 'Glass Ceilings' to 'Firewalls' - Different Metaphors for Describing Discrimination'." Gender, Work and Organization, Vol 17, No.5. pp. 612-634.

Böhmer, N. and Schinnenburg, H. (2016). "How gender and career concepts impact Global Talent Management", Employee Relations, Vol 38, No. 1. pp. 73-93.

Bozionelos, N., Al Ariss, A. and Porschitz, E., (2017) "International mobility of workers: new forms, processes, and outcomes", Personnel Review, Vol. 46, Issue: 2 , pp.I-V, https://doi.org/10.1108/ PR-08-2018-349

Bozkurr, Ö. And Mohr, A.T. (2011). "Forms of Cross-Border Mobility and Social Capital in Multinational Enterprises". Human Resource Management Journal, Vol. 21, No.2. pp. 138-155.

Brewster, C., Bonache, J., Cerdin, J.L. and Suutari, V. (2014). "Exploring Expatriate Outcomes". The International Journal of Human Resource Management, Vol 25, No.14. pp.1921-1937.

Brown, A. (2015) "Identities and Identity Work in Organisations". International Journal of Management Reviews, Vol 17, pp.20-40.

Caliguiri, P. and Bonache, J. (2016). "Evolving and enduring challenges in global mobility". Journal of World Business, Vol 51. pp. 127-141.

Christofides, L.N., Polycarpou, A. and Vrachimis, K. (2013) Gender wage gaps, 'sticky floors' and 'glass ceilings' in Europe. Labour Economics, Vol 21, pp. 86-102.

Cross, C. and Lineham, M. (2006). "Barriers to Advancing Female Careers in the HighTech Sector: Empirical Evidence from Ireland”, Women in Management. Vol 21, No. 1.pp. 28-39.

Dang, R., Nguyen, D.K. and Vo, L.C. (2014). "Does the Glass Ceiling Exist? A Longitudinal Study of Women's Progress on French Corporate Boards". The Journal of Applied Business Research, Vol 30, No 3. pp. 909-916. 
Daubner-Siva, D., Ybema, S., Vinkenburg, C.J. and Beech, N. (2018) "The talent paradox: talent management as a mixed blessing", Journal of Organizational Ethnography, Vol. 7 No.1, pp.74-86.

Duberley, J. and Carrigan, M. (2012). "The Career Identities of 'Mumpreneurs': Women's Experiences of Combining Enterprise and Motherhood". International Journal of Small Business, Vol 0, No. 0. pp. 1-23.

Ely, R.J. and Meyerson, D.E. (2010). An organizational approach to undoing gender: the unlikely case of offshore oil platforms. Research in Organizational Behavior, Vol 30, pp. 3-34.

Festing, M., Kornau, A. and Schäfer, L. (2015). “Think talent - think male? A comparative case study analysis of gender inclusion in talent management practices in the German media industry", The International Journal of Human Resource Management, Vol 26, No. 6. pp.707-732.

Gibbs, G.R. (2018) Analysing Qualitative Data ( $2^{\text {nd }}$ Ed). London: Sage Publications Ltd.

Gioia, D.A., Corley, K.G. and Hamilton, A.L. (2013). "Seeking Qualitative Rigor in Inductive Research: Notes on the Gioia Methodology," Organizational Research Methods, Vol 16, No. 1. pp. 15-31.

Glanz, L. (2003). "Expatriate Stories: A Vehicle of Professional Development Abroad". Journal of Managerial Psychology, Vol 18, No. 3. pp. 259-274.

Glass, C. and Cook, A. (2016). "Leading at the Top: Understanding Women's Challenges above the Glass Ceiling". The Leadership Quarterly, Vol 27, No. 1. pp. 5163.

Groutsis, D., O'Leary, J. and Russell, G. (2018) "Capitalizing on the cultural and linguistic diversity of mobile talent: lessons from an Australian study", The International Journal of Human Resource Management, Vol 29, No.15. pp. 2231-2252, DOI: 10.1080/09585192.2016.1239213.

Harvey, M., Napier, N. and Moeller, M. (2009). 'Interpreting Dual Career Couples' Family Life-Cycles: Identifying Strategic Windows of Global Career Opportunity". Research and Practice in Human Resource Management, Vol 17, No. 2. pp. 14-35.

Hassink, W. H.J. and Russo, G. (2010) The glass door: The gender composition of newly-hired workers across hierarchical job levels, IZA Discussion Papers, No. 4858, Institute for the Study of Labor (IZA), Bonn.

Holt, A. (2010). "Using the telephone for narrative interviews: A research note". Qualitative Research, Vol 10, No.1.pp. 113-121.

Howe-Walsh, L and Torka, N. (2017) "Repatriation and (perceived) organisational support (POS): The role of and interaction between repatriation supporters", Journal of 
Global Mobility: The Home of Expatriate Management Research, Vol. 5, No.1. pp.6077.

Huberman, A.M. and Miles, M.B. (2002). The Qualitative Researcher's Companion. London: Sage Publications Ltd.

Hultin, M. (2003) Some take the glass escalator; some hit the glass ceiling? Work and Occupations, Vol 30, No. 1. pp. 30-61.

Hutchings, K. and Michailova, S. (2017) "Female expatriates: towards a more inclusive view”. Chpt 12 pps. 241-260 in McNulty, Y. and Selmer, J. (Eds) Research Handbook of Expatriates, Gloucester: Edwood Elgar Publishing Limited.

Insch, G. S., McIntyre, N. and Napier, N.K. (2008). "The Expatriate Glass Ceiling: The Second Layer of Glass". Journal of Business Ethics, Vol 83. pp. 19-28.

Janssens, M., Cappellen, T. and Zanoni, P. (2006). "Successful Female Expatriates as Agents: Positioning through Gender, Hierarchy and Culture". Journal of World Business, Vol 41.pp. 133-148.

Jenkins, R. (2000) "Categorization: Identity, Social Processes and Epistemology", Current Sociology, Vol 48, No. 3. Pp. 7-25.

Jenkins, R. (2014) Social Identity. (4th). Oxon: Routledge.

Jeong, Y.J., Zvonkovic, A.M., Sano, Y. and Acock, A.C. (2013). "The occurrence and frequency of overnight job travel in the USA". Work, Employment and Society, Vol 27, No. 1. pp. 138-152.

Kohonen, E. (2005). "Developing Global Leaders through International Assignments". Personnel Review, Vol 34, No. 1.pp. 22-36.

Kirk, S. (2016). Career capital in global Kaleidoscope Careers: the role of HRM. The International Journal of Human Resource Management, Vol. 27, No. 6. pp. 681-697.

Lineham, M. and Walsh, J.S. (1999) "Senior female international managers: breaking the glass border", Women in Management Review, Vol. 14, Issue: 7, pp.264-272.

Lirio, P. (2014). "Taming travel for work-life balance in global careers", Journal of Global Mobility, Vol 2, No. 2. pp. 160-182.

Mäkelä, L, Saarenpää, K. and McNulty, Y. (2017) "International business travellers, short term assignees and international commuters", Chpt 14 pps. 276-294 in McNulty, Y. and Selmer, J. (Eds) Research Handbook of Expatriates, Gloucester: Edwood Elgar Publishing Limited.

Mäkelä, L., Suutari, V. and Mayerhofer, H. (2011). "Lives of Female Expatriates: Work-Life Balance Concerns". Gender in Management: An International Journal, Vol 26, No. 4. pp. 256-274. 
Mao, J. and Shen, Y. (2015). "Cultural identity change in expatriates: A social network perspective”. Human Relations, Vol 69, No. 10. pp. 1533-1566.

McNulty, Y. and Hutchings, K. (2016). "Looking for global talent in all the right places: a critical literature review of non-traditional expatriates". The International Journal of Human Resource Management, Vol 27, No. 7. pp. 699-728,

Ng, E.S. and Sears, G.J. (2017) "The glass ceiling in context: the influence of CEO gender, recruitment practices and firm internationalization on the representation of women in management". Human Resource Management Journal, https://doi.org/10.1111/1748-8583.12135.

Painter-Morland, M., Kirk, S., Deslandes, G. \& Tansley, C. (2018) 'Talent Management Discourses: An Ethical Analysis', European Management Review, DOI: 10.1111/emre.12171.

Powell, G.N. and Butterfield, A. (2015). "The Glass Ceiling: What have we learned 20 years on?" Journal of Organizational Effectiveness: People and Performance, Vol 2, No. 4. pp. 306-326.

Puchmüller, K. and Fischlmayr, I. (2017). "Support for female international business travellers in dual-career families", Journal of Global Mobility: The Home of Expatriate Management Research, Vol 5, No.1. Pp.22-42

Ramaswami, A., Huang, J.C. and Dreher, G. (2013). "Interaction of Gender, Mentoring, and Power-Distance on Career Attainment: A Cross-Cultural Comparison". Human Relations, Vol 67. pp.153-173.

Ryan, M. K., Haslam, S. A., Hersby, M. D., and Bongiorno, R. (2011). Think crisisthink female: The glass cliff and contextual variation in the think manager-think male stereotype. Journal of Applied Psychology, Vol 96, No 3. Pp. 470-484.

Scurry, T., Rodriguez, J.K. and Bailouni, S. (2013) "Narratives of identity of selfinitiated expatriates in Qatar", Career Development International, Vol. 18, No.1. pp.1233.

Shortland, S. (2018) "Female expatriates' motivations and challenges: the case of oil and gas", Gender in Management: An International Journal, Vol. 33 No.1. pp.50-65

Stoermer, S., Davies, S.E., Bahrisch, O. and Portniagin, F. (2017). "For sensation's sake: Differences in female and male expatriates' relocation willingness to dangerous countries based on sensation seeking", Journal of Global Mobility, Vol 5, No. 4. pp.374-390.

Sturges, J.E. and Hanrahan, K.J. (2004). "Comparing telephone and face-to-face qualitative interviewing: A research note”. Qualitative Research, Vol 4, No. 1. pp. 107118.

Sugiyama, K., Ladge, J.J. and Kenney, K. (2018) "Careers in construction: Developing career identity out of redefining moments", Academy of Management Proceedings, https://doi.org/10.5465/AMBPP.2018.122. 
Tansley, C. and Tietze, S. (2013) "Rites of passage through talent management progression stages: An identity work perspective". International Journal of Human Resource Management, Vol 24, No. 9. pp. 1799-1815.

Tienari, J., Vaara, E. and Meriläinen, S. (2010) "Becoming an international man: Top manager masculinities in the making of a multinational corporation", Equality, Diversity and Inclusion: An International Journal, Vol. 29, No.1, pp.38-52.

Trier-Bieniek, A. (2012). "Framing the telephone interview as a participant-centred tool for qualitative research: a methodological discussion". Qualitative Research, Vol 12, No.6. pp. 630-644.

Trzebiatowska, M. (2010) The advent of the 'Easy Jet Priest': Dilemmas of Polish Catholic Integration in the UK, Sociology, Vol. 44, No. 6. Pp. 1055-1072.

Varma, A. and Russell, L. (2016). "Women and expatriate assignments: Exploring the role of perceived organizational support", Employee Relations, Vol 38, No.2. pp.200223.

Watson, T.J. (2008). "Managing identity: Identity work, personal predicaments and structural circumstances”. Organization, Vol 15. pp. 121-142

Zeng, Z. (2011). "The Myth of the Glass Ceiling: Evidence from a Stock-Flow Analysis of Authority Attainment". Social Science Research, Vol 40. pp. 312-325. 